\title{
Solidarismo y contratos relacionales: alternativas frente a la pandemia de covid-19*-***
}

\section{Thea Christine Bauer ${ }^{* * *}$ \\ - Mariana Bernal Fandiño***}

RESUMEN. Los efectos de la pandemia han evidenciado la insuficiencia de herramientas jurídicas como la fuerza mayor o la imprevisión para hacer frente a las diversas dificultades que enfrentan los contratantes por circunstancias extraordinarias posteriores a la celebración de los acuerdos, más allá de la imposibilidad de cumplimiento o la excesiva onerosidad prestacional. Este artículo pretende analizar aproximaciones diferentes que puedan dar luces para encontrar una salida que tenga como norte una mayor justicia contractual, tales como la doctrina del solidarismo contractual y la teoría de los contratos relacionales.

PALABRAS ClAVE: incumplimiento contractual, pandemia, fuerza mayor, imprevisión, solidarismo contractual, teoría relacional.

* Fecha de recepción: 29 de julio de 2020. Fecha de aceptación: 26 de febrero de 2021.

Para citar el artículo: Bauer, T. C. y Bernal FAndiño, M., "Solidarismo y contratos relacionales: alternativas frente a la pandemia de covid-19", Revista de Derecho Privado, Universidad Externado de Colombia, n. ${ }^{\circ} 41$, julio-diciembre 2021, 53-80, Dor: https://doi.org/10.18601/01234366.n41.03.

** Este artículo es un producto del Grupo de Investigación en Derecho Privado de la Universidad de los Andes, Bogotá, Colombia.

*** Bucerius Law School, Hamburgo, Alemania; profesora. Magíster en Derecho, Universidad de Oxford, Oxford, Reino Unido. Doctora en Derecho, Bucerius Law School, Hamburgo, Alemania. Contacto: thea.bauer@law-school.de Orcid: 0000-0002-1891-7867.

**** Universidad de los Andes, Bogotá, Colombia; profesora asociada de la Facultad de Derecho. Doctora en Derecho, Pontificia Universidad Javeriana, Bogotá, Colombia. Magíster en Derecho Internacional Privado, Universidad de Paris ir Panthéon-Assas, París, Francia. Magíster en Derecho Comercial, Universidad de Paris II Panthéon-Assas, París, Francia. Abogada, Pontificia Universidad Javeriana, Bogotá, Colombia. Contacto: m.bernalf@uniandes.edu.co Orcid: 0000-0002-0193-0475. 


\title{
Contractual Solidarism and Relational Contract Theory: Alternative Approaches to Contract Law in Light of the Covid-19 Pandemic
}

\begin{abstract}
Aвstract. The effects of the pandemic have rendered obvious that legal instruments such as force majeure and unforeseeability are insufficient when facing difficulties caused by extraordinary circumstances after the moment of contract formation beyond impossibility of compliance or excessive onerous benefits. This article intends to analyze two different approaches which could offer a solution for the issue presented, while aiming to achieve greater contractual justice - namely the doctrine of contractual solidarism and relational contract theory.
\end{abstract}

KEYWORDS: breach of contract, pandemic, force majeure, unforeseeability, solidarism in contracts, relational contract theory.

Sumario. Introducción. I. Fuerza mayor. II. Teoría de la imprevisión. III. Solidarismo contractual. Iv. Teoría relacional de los contratos. v. El derecho que regula los contratos relacionales. vi. La teoría relacional de los contratos a la luz del covid-19. VII. Evaluación. Reflexiones finales. Referencias.

\section{Introducción}

El principio de la fuerza obligatoria de los contratos es necesario para el desarrollo de los negocios y para la vida en comunidad, por lo que sus excepciones han sido analizadas de manera restrictiva. Sin embargo, deben existir mecanismos que permitan evitar desequilibrios injustificados que atenten contra la equidad.

La función social de los contratos hoy se hace más clara que nunca; como lo afirma Hinestrosa, no puede imaginarse un negocio jurídico válido que esté desprovisto de "función social relevante o sin correspondencia con el 'principio social' o la utilidad pública", por lo que el derecho debe proteger esa función ${ }^{1}$. En este sentido, principios como la buena fe y la solidaridad son, entre otros, postulados que orientan los ordenamientos jurídicos, y en mayor medida en un Estado social de derecho ${ }^{2}$.

En muchos aspectos, los efectos del Covid-19 han causado extremas e imprevistas dificultades económicas para los contratantes. Por ejemplo, muchas personas, algunas de ellas especialmente vulnerables, han perdido sus trabajos, lo que ha dificultado gravemente la posibilidad de cumplir sus obligaciones. Las restricciones gubernamentales y la demanda decreciente de bienes y servicios desde que inició la

1 Hinestrosa, F., "Función, límites y cargas de la autonomía privada", Revista de Derecho Privado, Universidad Externado de Colombia, n. ${ }^{\circ}$ 26, 2014, 5-39.

2 Franco, J. A., "La excesiva onerosidad sobrevenida en la contratación mercantil: una aproximación desde la perspectiva de la jurisdicción civil en Colombia", Revista de Derecho Privado, Universidad Externado de Colombia, n. ${ }^{\circ} 23,2012,233-265$. 
pandemia, han llevado a que negocios de todo tipo estén luchando para poder pagar a sus empleados y acreedores y, en general, continuar con su actividad de cualquier manera posible ${ }^{3}$.

Los efectos de la pandemia han evidenciado la insuficiencia de las herramientas jurídicas tradicionales para hacer frente a muchos casos de incumplimiento contractual causado por circunstancias extraordinarias posteriores a la celebración de los acuerdos. Frente a esta situación, varios ordenamientos jurídicos han decidido adoptar diversas normas de emergencia para sortear todo tipo de dificultades en diferentes aspectos, entre ellos el contractual. Por lo anterior, en este artículo se plantean distintas aproximaciones dirigidas a encontrar una salida inspirada en una mayor justicia contractual.

Partiendo de la importancia de la obligatoriedad del vínculo contractual y de la necesidad de cumplir lo acordado, el presente estudio no pretende premiar la negligencia de las partes ni ignorar los abusos de quienes aleguen de manera arbitraria excusas para incumplir o terminar anticipadamente los contratos. El texto procura identificar opciones para dar una mayor flexibilidad a los contratos frente a circunstancias extraordinarias y difíciles de prever que puedan afectar su cumplimiento en los casos en los que las figuras de la fuerza mayor o la imprevisión no son aplicables.

Empezaremos entonces refiriéndonos a las figuras de la fuerza mayor y de la imprevisión como herramientas que se han utilizado para enfrentar imprevistos contractuales, y expondremos las razones por las cuales no consideramos que sean suficientes para afrontar la problemática que se está presentando en muchos casos de incumplimiento contractual en la actualidad.

Seguidamente analizaremos movimientos como el del solidarismo contractual y la teoría relacional de los contratos, al igual que la manera como estos pueden responder a la necesidad de mayor equilibrio y justicia en los contratos, necesidad que hoy más que nunca se hace evidente en la sociedad. La doctrina del solidarismo se orienta a exigir a las partes el cumplimiento de deberes de colaboración entre ellas, rechazando una visión individualista del derecho privado que suele ser indiferente frente a los desequilibrios contractuales ${ }^{4}$. Resulta de particular importancia, ante la coyuntura de la pandemia, el deber de renegociar que deben observar los contratantes en caso de verse seriamente afectados con las medidas empleadas por los gobiernos para mitigar la propagación del COVID-19. De manera similar, la teoría relacional desarrollada por Ian Macneil reacciona ante lo que considera una visión poco realista, planteada por la teoría clásica de los contratos. La mencionada postura reconoce

3 Los efectos de la pandemia han ocasionado un gran número de complicaciones legales así como la afectación de los procesos judiciales, impactando diversas áreas del derecho. Este artículo, sin embargo, solo pretende concentrarse en uno de los muchos problemas legales derivados de la pandemia: la situación de extrema dificultad en el pago de las obligaciones ocasionada por los efectos del COVID 19 después de celebrado el contrato.

4 Mazeaud, D., "Le nouvel ordre contractuel", Revue des contrats, n. ${ }^{\circ}$ 1, 2003, 295. 
que en las economías modernas se presenta una tensión entre la seguridad jurídica y la necesidad de enfrentar los cambios que afecten los contratos durante su ejecución.

\section{Fuerza mayor}

Aunque la fuerza mayor no se encuentra incorporada bajo esa denominación en todos los ordenamientos jurídicos, la idea de imposibilidad de ejecución se establece generalmente como un factor de exoneración ${ }^{5}$.

Según la teoría clásica de los contratos, la fuerza mayor comprende dos elementos fundamentales: la irresistibilidad y la imprevisibilidad, y conlleva como efecto la imposibilidad absoluta de cumplimiento de la obligación. El límite de la diligencia que se espera del deudor está representado por la irresistibilidad de los efectos del obstáculo para el cumplimiento, lo que permite unir la responsabilidad civil por daños con su exoneración por fuerza mayor o caso fortuito ${ }^{6}$.

Se ha señalado como requisito adicional de la fuerza mayor el de la exterioridad, es decir, que el hecho sea ajeno al círculo de control del sujeto. Así, una persona que conduzca un automóvil que se quede sin frenos y cause por ello un accidente no podría alegar fuerza mayor o caso fortuito para exonerarse de responsabilidad puesto que la revisión de los frenos es una situación que estaría bajo su control ${ }^{7}$.

Un posible origen de esta exigencia de exterioridad de la fuerza mayor puede encontrarse en el antiguo artículo 1147 c.c. francés que imponía al deudor justificar una causa extraña para exonerarse de responsabilidad ${ }^{8}$; este artículo fue reemplazado por el artículo 1231-1 en la reciente reforma del derecho de obligaciones y contratos que ya no menciona la causa extraña sino que se refiere directamente a la fuerza mayor?.

5 Cárdenas, J. P., "Causa extraña como eximente de responsabilidad", en Castro, M. (coord.), Derecho de las obligaciones, t. III, Bogotá, Universidad de los Andes, 2018, 415-472.

6 VIDAL, A., "Cumplimiento e incumplimiento contractual en el código civil: una perspectiva más realista", Revista Chilena de Derecho, vol. 34, n. ${ }^{\circ} 1,2007,41-59$.

7 CÁRdEnAs, J. P., “Causa extraña como eximente de responsabilidad”, cit., 415-472.

8 El antiguo artículo 1147 c.c. francés establecía: "Le débiteur est condamné, s'il y a lieu, au paiement de dommages et intérêts soit à raison de l'inexécution de l'obligation, soit à raison du retard dans l'exécution, toutes les fois qu'il ne justifie pas que l'inexécution provient d'une cause étrangère qui ne peut lui être imputé..." ("el deudor es responsable, si hay lugar a ello, al pago de daños y perjuicios ya sea en razón de la inejecución de la obligación, o en razón del retardo en la ejecución, siempre y cuando no justifique que la inejecución proviene de una causa extraña que no puede serle imputada...". Trad. propia).

9 El actual artículo 1231-1 c.c. francés dispone: "Le débiteur est condamné, s’il y a lieu, au paiement de dommages et intérêts soit à raison de l'inexécution de l'obligation, soit à raison du retard dans l'exécution, s'il ne justifie pas que l'exécution a été empêchée par la force majeure" ("el deudor es responsable, si hay lugar a ello, al pago de daños y perjuicios ya sea en razón de la inejecución de la obligación, o en razón del retardo en la ejecución, si no justifica que la ejecución ha sido impedida por fuerza mayor". Trad. propia). 
La exterioridad puede entenderse de dos maneras distintas: la ausencia de culpa en el sujeto o el rompimiento del vínculo causal, aunque predomina la posición subjetiva que se refiere a la culpa ${ }^{10}$.

No es fácil determinar la imposibilidad absoluta, se requiere acudir a un estándar de conducta para establecer si cualquier persona en las mismas circunstancias se encontraría frente a los mismos efectos perturbadores ${ }^{11}$. En los eventos de fuerza mayor se rompe el vínculo causal de la prestación afectada. Teniendo en cuenta lo anterior, es importante resaltar que la irresistibilidad se exige no solamente respecto del evento sino también de sus efectos. Por ello se presentan grandes discusiones en la actualidad con ocasión de la pandemia, pues la enfermedad del covid-19 puede ser imprevisible e irresistible pero no necesariamente lo serán las consecuencias que genere. La cuestión no gira entonces alrededor de la posibilidad de las prestaciones derivadas de los contratos, pues estas en muchos casos podrían cumplirse, sino de los derechos derivados de tales prestaciones que pueden ser impedidos o limitados por causas ajenas a las partes.

La ocurrencia de una situación de fuerza mayor no implica necesariamente la terminación del contrato. Pueden existir situaciones en las cuales, debido a un evento de fuerza mayor, se extinga la obligación para una de las partes, pero para la otra su obligación correlativa continúe, lo que analiza la teoría de riesgos. En Colombia, por ejemplo, la teoría de riesgos se establece en normas específicas para algunas situaciones $^{12}$, como la pérdida del cuerpo cierto debido en la compraventa, pero no hay una norma general al respecto. Por una parte, esta teoría genera que frente a muchos casos exista un vacío legal respecto de la obligación correlativa a la obligación que se extinguió por fuerza mayor. Por otra parte, en muchas de las circunstancias actuales que se viven a causa de la pandemia los bienes o servicios no han perecido, existen y su cumplimiento en algunos casos es posible, pero los derechos correlativos están limitados por decisiones gubernamentales para evitar la propagación del virus.

Tomemos como ejemplo el contrato de arrendamiento, que es uno de los contratos más intervenidos por el Estado por su impacto social y económico. En el arrendamiento de vivienda no habría lugar a pensar en fuerza mayor, pues no hay imposibilidad absoluta de cumplir ni la obligación del arrendador ni la del arrendatario. El arrendatario está utilizando el bien, así que el arrendador está cumpliendo

10 Brantt, M. G., "La exigencia de exterioridad en el caso fortuito: su construcción a partir de la distribución de los riesgos del contrato", Revista de Derecho de la Pontificia Universidad Católica de Valparaíso, n. ${ }^{\circ} 33,2009,39-102$. Esta autora propone una visión distinta de la exterioridad como requisito de la fuerza mayor al estimar que esta ajenidad "supone necesariamente considerar la distribución del riesgo del incumplimiento realizada por las partes a través del propio contrato".

11 Colombia, Corte Suprema de Justicia, Sala Civil, sentencia del 26 de enero de 1982.

12 Sobre la teoría de riesgos, véase TERnERA, F., "Las pérdidas fortuitas de los bienes debidos: teoría de los riesgos de los contratos sinalagmáticos", en CASTRo, M. (coord.), Derecho de las obligaciones, t. I, Bogotá, Universidad de los Andes, 2011, 477-504. 
su obligación. Y la obligación del arrendatario, al ser una obligación de dinero, de género, en principio siempre es de posible cumplimiento.

El arrendamiento de local comercial presenta otras dificultades. Se pueden presentar distintos escenarios para analizar si nos encontramos o no frente a un caso de fuerza mayor. Desde una visión tradicional, habrá fuerza mayor si la imposibilidad de abrir el local es total y absoluta, no si es una cuestión temporal o parcial. Surge la inquietud entonces de si el arrendatario debiera continuar pagando un canon por un local que no puede utilizar.

Pensemos en casos en los cuales la legislación de emergencia permite el uso del local parcialmente, solo para domicilios (take away), por ejemplo; o si exige disminuir la cantidad de personas permitidas en el establecimiento; o si bajan las ventas sustancialmente porque hay menos personas en las calles o el poder adquisitivo de los consumidores disminuye por el aumento del desempleo; entre otros.

En los casos anteriores, las limitaciones o prohibiciones en los usos de los locales comerciales pueden no afectar la prestación debida, pero pueden generar muchas dificultades para su cumplimiento, situación que los ordenamientos jurídicos generalmente enfrentan mediante normas sobre insolvencia personal o empresarial.

Las limitaciones del concepto tradicional de fuerza mayor han generado interesantes reflexiones como las de la doctrina nórdica sobre la noción de fuerza mayor social $^{13}$ para referirse a circunstancias externas al deudor, que le impiden cumplir íntegra y oportunamente con sus obligaciones, pero que puedan considerarse suficientes para atenuar las sanciones frente al incumplimiento. Este análisis se centra particularmente en el incumplimiento de las deudas dinerarias, donde estas sanciones se activan de forma automática y afectan a la población más vulnerable.

Como lo señala Goldenberg, la fuerza mayor social requiere de la acreditación de tres elementos: primero, que el deudor se encuentre afectado por alguna circunstancia especial, como quedarse sin empleo o sufrir una enfermedad grave; segundo, el nexo causal con la incapacidad de pago, y tercero, que la situación sea imprevista y no imputable al deudor ${ }^{14}$. Los efectos jurídicos pasan por la mitigación de indemnizaciones o cláusulas penales; por el impedimento de resolver el contrato si es de aquellos de primera necesidad, o, por el contrario, de darlo por terminado sin lugar a sanciones, dependiendo del caso ${ }^{15}$.

13 Wilhelmsson, T., "“Social Force Majeure'. A New Concept in Nordic Consumer Law”, Journal of Consumer Policy, n. ${ }^{\circ}$ 13, 1990, 1-14.

14 Goldenberg, J. L., “A propósito del Covid-19: incapacidad sobreviniente de pago y 'fuerza mayor social"”, El Mercurio, 4 de abril de 2020, disponible en: https://www.elmercurio.com/Legal/Noticias/Opinion/2020/04/27/A-proposito-del-covid19-incapacidad-sobreviniente-de-pago-y-fuerzamayor-social.aspx [consultado el 28 de julio de 2020]. 
Esta visión más amplia de la fuerza mayor ${ }^{16}$ puede ser de gran utilidad en cualquier tiempo, y aún más cuando existen, como ahora, circunstancias generalizadas que agudizan las situaciones de vulnerabilidad de un gran número de contratantes.

\section{Teoría de la imprevisión}

Diferente es la situación que se presenta en la figura de la imprevisión, según la cual el contrato debe ser revisado si por circunstancias sobrevinientes se altera de manera excesiva su equilibrio ${ }^{17}$. La diferencia fundamental con la fuerza mayor radica en que mientras esta implica una imposibilidad total de cumplimiento, la teoría de la imprevisión genera una imposibilidad relativa pues el cumplimiento de la prestación por parte del afectado aún es posible pero las circunstancias sobrevinientes afectaron gravemente el equilibrio prestacional del acuerdo.

Se ha encontrado que el origen de la teoría se ubica en la Edad Media con el derecho canónico; sin embargo, el antecedente hito que suele identificarse con la imprevisión consiste en la decisión del Consejo de Estado francés en 1916 sobre el caso Gas de Burdeos ${ }^{18}$.

En Colombia, esta figura está consagrada en el artículo 868 c. de co. y tiene como finalidad una revisión judicial para determinar si el contrato puede ajustarse para recuperar el equilibrio prestacional del contrato o, de no ser ello posible, darlo por terminado. Según esta norma, procede tal revisión por el advenimiento de circunstancias que eran imprevistas o imprevisibles en la época de celebración de un contrato de ejecución sucesiva, periódica o diferida que alteren o agraven la prestación de futuro cumplimiento a cargo de una de las partes. Es posible aplicar esta teoría cuando el riesgo por tales circunstancias no fue asumido por la parte afectada ${ }^{19}$.

La imprevisión se asemeja a la excesiva onerosidad sobreviniente, aunque se diferencian pues esta última proviene de una cláusula explícita que acuerdan las partes y sus criterios de aplicación son generalmente más laxos que los de la primera ${ }^{20}$.

Se ha debatido, recientemente, si lo que está afectando gravemente el cumplimiento de algunos contratos con ocasión de las decisiones legales para enfrentar el brote de COVID-19 puede analizarse bajo la teoría de la imprevisión. Si bien existen

16 Una aproximación más amplia de la fuerza mayor también se encuentra en el artículo 7.1.7 de los Principios Unidroit que permite la suspensión de la ejecución de la obligación cuando el impedimento es solamente temporal.

17 Hinestrosa, F., "Teoría de la imprevisión”, Revista de Derecho Privado, Universidad Externado de Colombia, n. ${ }^{\circ} 39,2020,9-29$.

18 Franco, J. A., "La excesiva onerosidad sobrevenida en la contratación mercantil: una aproximación desde la perspectiva de la jurisdicción civil en Colombia", cit., 233-265.

19 CAro, J., "La teoría de la imprevisión", en CAStro, M. (coord.), Derecho de las obligaciones, t. II, Bogotá, Universidad de los Andes, 2016, 121-162.

20 Alterini, A., Treinta estudios de derecho privado, Bogotá, Temis-Pontificia Universidad Javeriana, 2011,332 . 
casos en los que puede presentarse un desequilibrio prestacional con ocasión de la pandemia, en muchos otros casos las prestaciones no se han alterado. Tomemos, nuevamente, el ejemplo del contrato de arrendamiento, que ayuda a ilustrar la complejidad de la problemática. En casos de arrendamiento de vivienda, se están evidenciando las dificultades económicas del arrendatario de pagar su obligación porque perdió su trabajo, su empresa está cerrada, no tiene ingresos en esta época, etc. La jurisprudencia colombiana ha señalado que la imprevisión se aplica solo cuando existe un desequilibrio en las prestaciones, de manera que si lo que ha cambiado es la capacidad de pago del arrendatario no opera la figura, pues el suceso está en la esfera o círculo del riesgo de la parte afectada ${ }^{21}$. Esta característica, sumada a los estrictos requisitos de la regulación de la figura en el código de comercio colombiano, ha convertido la imprevisión en una institución de poca utilidad práctica en este país.

\section{Solidarismo contractual}

El solidarismo, como filosofía contractualista, empieza a desarrollarse en Francia al final del siglo XIX como una respuesta a los excesos del individualismo en los contratos. Bourgeois, en su obra Solidaridad, sentó las bases de este movimiento que se funda en el reconocimiento del hombre como un ser social que como tal depende de los otros ${ }^{22}$. Duguit, adicionalmente, explica que la solidaridad consiste únicamente en la realización de acciones positivas que les permitan a los demás ejercer sus derechos y desarrollar sus propias potencialidades ${ }^{23}$.

Se ha considerado que dos elementos identifican este movimiento: el vínculo de solidaridad entre las partes y la conciliación de sus intereses ${ }^{24}$. El solidarismo es una doctrina que exige el cumplimiento de los principios de lealtad, solidaridad y buena fe al afirmar la obligación que tienen las partes de colaborar en sus acuerdos ${ }^{25}$. Adicionalmente, se ha sostenido que el solidarismo reposa en las ideas de la función social que tienen los contratos y en la búsqueda del equilibrio contractual ${ }^{26}$.

Desde una perspectiva solidarista, se ha considerado que la función social del contrato está relacionada con el vínculo de solidaridad entre las partes; el contrato debe ser un mecanismo de colaboración en virtud del cual los contratantes deben actuar dentro de unos parámetros de equilibrio ${ }^{27}$.

22 Bourgeois, L., La solidarité, Villeneuve-d'Ascq, Presses Universitaires du Septentrion, 1998.

23 Duguit, L., Las transformaciones generales del derecho privado desde el Código de Napoleón, Madrid, Francisco Beltrán, 1920.

24 Courdier-Cuisiner, A. S., Le solidarisme contractuel, Paris, Litec-Editions du JurisClasseur, 2006.

25 Ibid.

26 Bernal, M., El deber de coherencia en el derecho colombiano de los contratos, Bogotá, Pontificia Universidad Javeriana, 2013. 
La idea de colaboración entre los contratantes encuentra un fundamento importante en los desarrollos del principio general de la buena fe. En virtud de la función integradora de este principio, se entienden comprendidos dentro del contenido del contrato ciertos deberes aun sin haber sido expresamente pactados por las partes. Entre estos deberes, colaterales o secundarios de conducta, se encuentran los deberes de información, lealtad, confidencialidad, consejo, protección y coherencia, entre otros ${ }^{28}$. Autores italianos como Betti ${ }^{29}$ o Bianca ${ }^{30}$ evidencian la relación entre solidaridad y buena fe precisamente por las exigencias del recto obrar contractual y el deber de cooperación entre las partes ${ }^{31}$.

Otra forma de entender la función social de los contratos va más allá de la colaboración que se deben los contratantes pues se refiere a la posibilidad del Estado de intervenir en los negocios de los particulares. En efecto, el Estado social implica, desde esta perspectiva, la posibilidad de que el Estado intervenga en la autonomía privada para promover el desarrollo económico y social, pues la voluntad de los individuos no puede alejarse del contexto social, lo que resulta claro en las condiciones actuales.

Resulta de gran relevancia para analizar la función social del contrato referirnos a la legislación brasileña. El código civil del Brasil consagra en su artículo 421 que "la libertad de contratar será ejercida en razón y dentro de los límites de la función social del contrato". Esta disposición ha sido muy discutida pues los alcances de la función social del contrato no son claros ${ }^{32}$.

El modelo de contrato que adopta la legislación brasileña, para algunos, es una cláusula general que exige que el contrato esté al servicio de la realización del principio de la socialidad, lo que implica que las relaciones del derecho privado, en diferentes oportunidades, pueden ser de interés para la sociedad en su conjunto, lo que justifica la intervención estatal ${ }^{33}$. La directriz constitucional de la solidaridad social

28 Solarte, A., "La buena fe contractual y los deberes secundarios de conducta", Vniversitas, Pontificia Universidad Javeriana, vol. 53, n. ${ }^{\circ}$ 108, 2004, 281-315.

29 Betti, E., Teoría general de las obligaciones, t. I, J. L. de los Mozos (trad.), Madrid, Revista de Derecho Privado, 1969.

30 Bianca, M., Derecho civil, III, El contrato, F. Hinestrosa y É. Cortés (trads.), Bogotá, Universidad Externado de Colombia, 2007.

31 En el mismo sentido Pico ZúñIga, F. A. y Rojas Quiñones, S. A., Solidarismo contractual. El deber de cooperación y su repercusión en la responsabilidad civil, Bogotá, Ibáñez, 2013, afirman que el solidarismo contractual encuentra su fundamento en principios como la buena fe negocial y los deberes de cooperación y solidaridad.

32 Sobre el alcance de la función social de los contratos en Brasil, véase Branco, G., Função social dos contratos, São Paulo, Saraiva, 2009.

33 Branco, G. L. C., "Libertad contractual y su funcionalización: orientación metodológica y lenguaje utilizados por la comisión elaboradora del código civil brasileño", Vniversitas, Pontificia Universidad Javeriana, n. ${ }^{\circ}$ 123, 2011, 347-371. 
del derecho brasileño se proyecta en las normas de derecho privado desarrollando el principio de la socialidad ${ }^{34}$.

Según Benetti Timm, la doctrina brasileña parece haber llegado a un cuasi consenso sobre el sentido de la función social del contrato que "consistiría en promover la solidaridad, corregir el desequilibrio de poder implícito en el contrato y distribuir

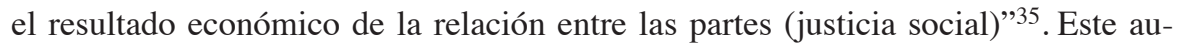
tor considera que esta visión se encuentra principalmente dentro del contexto de la sociología colectivista y solidarista de Comte, Durkheim y Tonnies ${ }^{36}$, padres del movimiento solidarista.

En el derecho colombiano podemos encontrar el fundamento de esta función social de los contratos, en primera medida, en la consagración constitucional de un Estado social de derecho, así como en los principios de buena fe y solidaridad establecidos igualmente en la Constitución Política.

La doble perspectiva de la función social del contrato conlleva, por una parte, deberes de cooperación para los contratantes y, por otra parte, la posibilidad del Estado de intervenir en los contratos, lo que se ha reflejado en las decisiones de varios países al crear normas transitorias que apoyen a las personas que se han visto más afectadas con la pandemia ${ }^{37}$.

Dentro de los deberes de cooperación de los contratantes encontramos que el deber de renegociar cobra un interés particular en el contexto de la pandemia. Recientemente se publicó en Colombia un artículo de opinión que afirmaba que en el ordenamiento jurídico colombiano no existe un deber de renegociar ${ }^{38}$. Creemos que esto no es cierto, pues el principio de buena fe integra al contenido del contrato el deber de renegociar las cláusulas pactadas por el acaecimiento de hechos sobrevinientes que provoquen un desajuste o desequilibrio económico en perjuicio de una o ambas partes sin que medie culpa ${ }^{39}$. La solución ideal frente a esta situación siempre será la renegociación, porque son las partes del contrato quienes se encuentran en la

34 Martins-Costa, J., "Reflexões sobre o princípio da função social dos contratos", Revista Direito GV, vol. $1, \mathrm{n} .^{\circ} 1,2005,41-66$.

35 Benetti Timm, L. "La función social del derecho contractual en el código civil brasileño: justicia distributiva vs. eficiencia económica", Revista de Instituciones, Ideas y Mercados, n. ${ }^{\circ}$ 52, 2010, 5-51.

36 Ibid.

37 Acerca de las normas adoptadas por diferentes ordenamientos con ocasión de la pandemia, véase GEBREKIDAN, S., "Frente al coronavirus los gobiernos van amasando poder (no todos son autócratas)", New York Times, 1 de abril de 2020, disponible en: https://www.nytimes.com/es/2020/04/01/ espanol/coronavirus-decreto-emergencia-autocratas.html [consultado el 28 de julio de 2020].

38 Revista Dinero, "Los contratos en la era del coronavirus", 18 de abril de 2020, disponible en: https:// www.dinero.com/empresas/articulo/asi-funcionan-los-contratos-en-la-era-del-coronavirus/284144 [consultado el 28 de julio de 2020].

39 Sobre la relación del principio de la buena fe como fundamento del deber de renegociar, véase Momberg URIBe, R., "La revisión del contrato por las partes: el deber de renegociación como efecto de la excesiva onerosidad sobreviniente", Revista Chilena de Derecho, vol. 37, n. ${ }^{\circ}$ 1, 2010, 43-72. 
mejor posición para regular sus intereses y conocen sus circunstancias particulares para ajustar el contrato poniéndose en el lugar del otro.

La pregunta que lógicamente se presenta frente a la anterior propuesta es: ¿qué ocurre si una de las partes se niega a negociar o no acepta una propuesta razonable y justa para ambas partes dadas las circunstancias especiales de cada una? Comparto la opinión de quienes consideran que la parte afectada podría pedir indemnización de perjuicios ${ }^{40}$.

Ahora bien, con la crisis sanitaria mundial hemos encontrado que distintos ordenamientos han expedido decretos de emergencia en diversas materias, y en contratación privada la atención se ha fijado especialmente en el contrato de arrendamiento por el impacto social que genera y los principios que entran en juego.

Revisando el derecho comparado, vale la pena destacar los decretos del derecho español en materia de contrato de arrendamiento. Son decretos que si bien no pueden tener en cuenta todo el abanico de posibilidades que puede presentarse en las relaciones entre arrendador y arrendatario, sí tienen en consideración importantes criterios para regular diferentes supuestos. El Decreto 11 del 31 de marzo de 2020 se refiere a los contratos de arrendamiento de vivienda, mientras que el Decreto 15 del 21 de abril de 2020 se refiere a los contratos de arrendamiento de local comercial.

Sobre los contratos de arrendamiento de vivienda, el decreto español adopta medidas dirigidas a familias y colectivos vulnerables. La norma define criterios para determinar esa situación de vulnerabilidad y requisitos para su acreditación, entre otros, no se tiene en cuenta solamente la situación de una persona, sino que se analizan los ingresos de la unidad familiar.

La determinación de los mencionados criterios es muy importante, pues las circunstancias actuales no se pueden prestar para que personas que no presentan una vulnerabilidad especial tomen ventaja de la crisis para obtener beneficios injustificados.

El solidarismo ha tenido muchos detractores, desde quienes critican la doctrina por considerarla utópica hasta los que consideran que atenta contra la seguridad jurídica ${ }^{41}$.

Sin embargo, acostumbrados a despojar de humanidad a las relaciones contractuales, se necesitó una pandemia para recuperar la importancia de la solidaridad y la capacidad de reconocernos en el otro.

40 Solarte, A., "La buena fe contractual y los deberes secundarios de conducta", cit., 281-315; RoJAS, S., "Responsabilidad civil por falta de cooperación contractual. Relevancia en tiempos del Covid-19”, In Casu - Blog, Instituto Colombiano de Responsabilidad Civil y del Estado, 2020, disponible en: https:/www.iarce.com/responsabilidad-civil-por-falta-de-cooperacion-contractualrelevancia-en-tiempos-del-covid-19/ [consultado el 28 de julio de 2020].

41 Mantilla, F., "El solidarismo contractual en Francia y la constitucionalización de los contratos en Colombia", Revista Chilena de Derecho Privado, n. ${ }^{\circ}$ 16, 2011, 187-241. 


\section{Teoría relacional de los contratos}

La teoría relacional de los contratos se introdujo por el profesor estadounidense Ian Macneil en la década de 1960 y ha evolucionado desde entonces ${ }^{42}$. Macneil desarrolló la teoría como una crítica a la teoría contractual clásica y neoclásica ${ }^{43}$, que no encontró compatible con una porción considerable del comportamiento contractual que se evidenciaba en la vida real.

\section{A. Derecho contractual clásico y neoclásico - La transacción discreta}

El derecho contractual clásico englobaba el derecho de contratos del siglo XIX, alcanzando su clímax en la obra de Samuel Williston, The Law of Contracts (1920), $\mathrm{y}$ en el Restatement of Contracts $(1932)^{44}$. Se caracterizaba por la idea de transacciones discretas, que son completamente independientes de cualquier otra relación pasada, presente o futura entre las partes ${ }^{45}$. El derecho que regula las transacciones discretas se enfocaba de manera casi exclusiva en el momento que se produce el "consentimiento objetivo"46, realzando así la "presentificación" (presentiation) ${ }^{47}$. La teoría clásica restringe las fuentes de la interpretación del contrato y le atribuye un mayor valor hermenéutico a la comunicación explícita, formal y lingüística que

42 La teoría relacional de los contratos se origina en el pensamiento jurídico (anglo-) americano. Por lo tanto, este artículo se centrará en la versión original de la teoría relacional de los contratos presentada por Ian Macneil. Sin embargo, es importante señalar que esta teoría (o versiones de la misma) ha sido adaptada por juristas de otras jurisdicciones, entre estas, algunas latinoamericanas. Acerca de la literatura latinoamericana sobre el tema, véase, para Colombia: BERnAL, M., "La contratación proactiva dentro de las nuevas visiones del contrato", Vniversitas, Pontificia Universidad Javeriana, vol. 64, n. ${ }^{\circ}$ 130, 2011, 21-52 y MARTínez OchOA, S., "Teoría relacional de los contratos: una visión alternativa del derecho de contratos", Revista de Derecho Privado, n. ${ }^{\circ} 35,2005,203-229$; para Brasil: Ambrozini, L. C. S. y Martineldi, D. P., "Contratos formales y relacionales entre organizaciones: proposición de un modelo para el análisis de las características transaccionales y las estructuras de gobernanza a partir de casos comparativos", Revista de Administração, vol. 52, n. ${ }^{\circ} 4,2017,374-391$; y, para Chile: Momberg Uribe, R. y Pino Emhart, A., "Los contratos de larga duración en la edición 2016 de los Principios Unidroit sobre contratos comerciales internacionales", Revista Chilena de Derecho Privado, n. ${ }^{\circ}$ 30, 2018, 163-191.

43 Ambas teorías se encuentran incluidas dentro del término derecho contractual tradicional; véase MACNEIL, I. R., "Contracts: Adjustment of Long-Term Economic Relations under Classical, Neoclassical, and Relational Contract Law”, Northwestern University Law Review, vol. 72, n. ' 6, 1978, 854 , nota 2 .

44 Ibid., 854, nota 2; FeInman, J. M., "Relational Contract Theory in Context", Northwestern University Law Review, vol. 94, n. $3,2000,738$.

45 Macneil, I. R., "Contracts: Adjustment of Long-Term Economic Relations under Classical, Neoclassical, and Relational Contract Law", cit., 856.

46 Véase ibid., 884; en el mismo sentido, Eisenberg, M. A., "Why There Is No Law on Relational Contracts", Northwestern University Law Review, vol. 94, n. ${ }^{\circ}$ 3, 2000, 807.

47 Macneil, I. R., "Contracts: Adjustment of Long-Term Economic Relations under Classical, Neoclassical, and Relational Contract Law", cit., 862. "Presentificación” (presentiation) significa limitar los resultados futuros esperados de una transacción a los especificados en el presente, especialmente al momento de la transacción; véase ibid., 863 . 
a la comunicación implícita, informal y no lingüística ${ }^{48}$. Adicionalmente, si la presentificación inicial no se materializa, el derecho otorga solo un número limitado de remedios y se rehúsa a habilitarlos en caso de producirse daños inesperados, produciendo así los efectos de una inejecución previsible en el momento de la formación del contrato ${ }^{49}$. Si las circunstancias cambian en el curso de una transacción, la posibilidad de reacomodar el riesgo de pérdida entre las partes es muy pequeña ${ }^{50}$, y no existe posibilidad alguna de compartir los riesgos a través de la cooperación ${ }^{51}$. En síntesis, el derecho contractual clásico se puede describir como "axiomático, deductivo, objetivo, estandarizado, estático, basado en la idea de agentes que no se conocen entre sí negociando en un mercado perfecto y en un modelo de actores racionales" 52 .

El derecho contractual neoclásico, que se encuentra en el artículo 2 U.C.C. y en el Restatement (Second) of Contracts ${ }^{53}$, está basado estructuralmente en el derecho clásico. Sin embargo, lo modifica en algunos aspectos, especialmente al permitir la planeación para la flexibilidad de contratos de largo plazo $^{54}$, y también al permitir a las partes librarse de los efectos producidos por un cambio de circunstancias ${ }^{55}$. Aun así, la meta del derecho neoclásico no es mantener unido el contrato, sino desarmarlo para distribuir las pérdidas de una manera más equitativa ${ }^{56}$ que en el enfoque clásico del todo o nada. Dado un cambio eventual, el sistema neoclásico sigue buscando preeminentemente en el acuerdo original para responder cómo se deben ajustar los cambios de circunstancias ${ }^{57}$.

\section{B. La crítica de Macneil. La incrustación de los contratos discretos}

La teoría relacional de los contratos reconoce que en las economías modernas existe un conflicto constante entre la demanda de estabilidad y la demanda de reacción al

48 Ibid.

49 Ibid., 864.

50 El derecho dejará la pérdida donde haya caído. En la mayoría de los casos, las pérdidas tendrán que ser asumidas por los proveedores de bienes y servicios; véase ibid., 861 .

51 Un cambio en las pérdidas siempre será total y no compartido; véase ibid.

52 EISENBERG, "Why There Is No Law on Relational Contracts", cit., 805 y ss., trad. propia; con una crítica del derecho contractual clásico en pp. 808 y ss.

53 MacneIL, I. R., "Contracts: Adjustment of Long-Term Economic Relations under Classical, Neoclassical, and Relational Contract Law", cit., 854, nota 2; Feinman, J. M., "Relational Contract Theory in Context", cit., 738 y ss.

54 MacneIL, I. R., "Contracts: Adjustment of Long-Term Economic Relations under Classical, Neoclassical, and Relational Contract Law”, cit., 865 y ss., con ejemplos.

55 Ibid., 875.

56 Ibid.

57 Ibid., 886. 
cambio $^{58}$. Siguiendo un enfoque de law-and-society, Macneil encontró que el derecho contractual tradicional representa un panorama de la contratación que no es realista ${ }^{59}$. Por ejemplo, el concepto de una transacción completamente discreta es en la mayoría de -si no en todos- los casos una ilusión ${ }^{60}$. Lo mismo puede decirse de la presentificación pura ${ }^{61}$. La razón es que, "en la vida real, incluso la más aparente transacción discreta está profundamente incrustada en las relaciones sociales" ${ }^{62}$. En el entendimiento amplio de relación presentado por Macneil, "cualquier estructura social común" establece "al menos los rudimentos de una relación por fuera de la transacción". Las relaciones ya han sido creadas por "un lenguaje común, un sistema de orden (lo que incluye derechos de propiedad y libertad), un sistema monetario y [...] un sistema legal que hace cumplir las promesas" "63. Así las cosas, una transacción completamente discreta solo puede ocurrir entre completos extraños que concurren incidentalmente y con la certeza de que nunca se volverán a cruzar de nuevo ${ }^{64}$.

\section{La teoría relacional de los contratos}

Macneil precisa que la teoría contractual se informa de cuatro proposiciones centrales:

(1) Toda transacción está incrustada en relaciones complejas. (2) Comprender cualquier transacción requiere comprender todos los elementos de las relaciones que la rodean. (3) El análisis efectivo de cualquier relación requiere reconocimiento y consideración de todos los elementos esenciales de las relaciones que la rodean que puedan llegar a afectar significativamente la transacción. (4) Un análisis combinado del contexto de las relaciones y las transacciones es más eficiente y produce un

58 Ibid., 854.

59 Véase también Eisenberg, M. A., "Why There Is No Law on Relational Contracts", cit., 808: "todo aspecto de esa escuela jurídica era incorrecto".

60 MacneIl, I. R., "Contracts: Adjustment of Long-Term Economic Relations under Classical, Neoclassical, and Relational Contract Law", cit., 856, 883; véase asimismo EISENBERG, M. A., "Why There Is No Law on Relational Contracts", cit., 816.

61 Macneil, I. R., "Contracts: Adjustment of Long-Term Economic Relations under Classical, Neoclassical, and Relational Contract Law", cit., 883.

62 Ibid., 857, nota 10; trad. propia, énfasis añadido; véase también MACNEIL, I. R., "Relational Contract: What We Do and Do Not Know", Wisconsin Law Review, University of Wisconsin Law School, vol. 1985, n. ${ }^{\circ}$ 3, 1985, 485, nota 7; MACNEIL, I. R., "Relational Contract Theory: Challenges and Queries", Northwestern University Law Review, vol. 94, n. . 3, 2000, 884.

63 MacneIL, I. R., "Relational Contract: What We Do and Do Not Know”, cit., 485, nota 7, trad. propia; explicado con mayor detalle en MACNEIL, I. R., "Relational Contract Theory: Challenges and Queries", cit., 884 .

64 Macneil, I. R., "Contracts: Adjustment of Long-Term Economic Relations under Classical, Neoclassical, and Relational Contract Law”, cit., 856. En la medida en que puedan rotularse las transacciones como discretas, el término correcto sería bastante discretas; véase Ibid., 856 y ss., con ejemplos de transacciones bastante discretas. 
producto analítico final más completo y certero que el que se produciría al iniciar un análisis no-contextual de las transacciones (traducción propia) ${ }^{65}$.

La teoría contractual relacional se basa en la observación de que, en la realidad, los contratos no se crean integralmente en el momento de su formación. A menudo, las partes empiezan a ejecutarlos antes de acordar todos los términos. Además, a lo largo de su vida útil, los contratos se expanden y evolucionan ${ }^{66}$. Esto es deseado y previsto por las partes, porque ven su contrato no como un medio para distribuir riesgos, sino como un medio para crear una relación recíproca. El aspecto relacional del contrato también informa su ejecución, que se lleva a cabo frecuentemente de acuerdo con el entendimiento de las partes y no según los términos expresos del contrato. Si existe incumplimiento de deberes contractuales, las partes van a (y esperan) resolver la disputa en sus propios términos en vez de hacer cumplir remedios contractuales. Por lo tanto, existe un consenso general en el sentido de que en la realidad el acuerdo de papel no refleja el acuerdo real, y de que las expectativas verídicas de las partes no se documentan en el acuerdo escrito ${ }^{67}$. En resumen, la teoría relacional de los contra$\operatorname{tos}^{68}$ se puede caracterizar como "abierta, inductiva, individualizada, dinámica, basada en el paradigma de transacciones de actores que están en una relación en curso, pero no basada en la psicología de actores racionales" 69 . Es una "imagen invertida" de la teoría clásica contractual ${ }^{70}$, y un refinamiento de la teoría neoclásica ${ }^{71}$.

A pesar de que virtualmente todos los contratos son relacionales ${ }^{72}$, la teoría relacional de los contratos afirma que existe una subcategoría de contratos que se

65 MacneIL, I. R., "Relational Contract Theory: Challenges and Queries", cit., 881.

66 Véase Macaulay, S., "The Real and the Paper Deal: Empirical Pictures of Relationships, Complexity and the Urge for Transparent Simple Rules", en CAmpBell, D. et al. (coords.), Implicit Dimensions of Contract: Discrete, Relational, and Network Contracts, Oxford, Hart, 778, con referencias adicionales.

67 Macaulay, S., "The Real and the Paper Deal: Empirical Pictures of Relationships, Complexity and the Urge for Transparent Simple Rules", cit., 51, 101 y ss.; véanse también las explicaciones en pp. 53 y ss.

68 En su trabajo posterior, Macneil utiliza la expresión "teoría esencial de los contratos" en vez de "teoría relacional de los contratos"; véase MACNEIL, I. R., "Relational Contract Theory: Challenges and Queries", cit., 893.

69 Eisenberg, M. A., "Why There Is No Law on Relational Contracts", cit., 812 y ss., trad. propia; adicionalmente, véase Feinman, J. M., "Relational Contract Theory in Context", cit., 748.

70 Eisenberg, M. A., "Why There Is No Law on Relational Contracts", cit., 812; véase también CAMPBELL, D., "Ian Macneil and the Relational Theory of Contract", en CAMPBELL, D. (coord.), Relational Theory of Contract: Selected Works of Ian Macneil, London, Sweet \& Maxwell, 2001, 42: "programas rivales".

71 Feinman, J. M., "Relational Contract Theory in Context", cit., 740.

72 Macneil, I. R., "Relational Contract Theory: Challenges and Queries", cit., 894 y s; EisenBerg, M. A., "Why There Is No Law on Relational Contracts", cit., 817; CAmpbell, D., "Ian Macneil and the Relational Theory of Contract", cit., 41. 
denominan contratos relacionales ${ }^{73}$. La esencia de la teoría relacional recae entonces en los diez patrones y normas comunes del comportamiento contractual, que de acuerdo con Macneil son el fundamento de todo contrato:

(1) integridad de rol (requerir consistencia, involucrar conflicto interno y ser inherentemente complejo); (2) reciprocidad (simplemente entendida como el principio de recibir una cosa a cambio de algo que se ha dado); (3) implementación de planeación; (4) realización del consentimiento; (5) flexibilidad; (6) solidaridad contractual; (7) la restitución, dependencia y los intereses de expectativa (las 'normas vinculantes'); (8) creación y restricción de poder (la 'norma de poder'); (9) propiedad de los medios, y (10) armonización con la matriz social particular (patrones del comportamiento y normas supracontractuales $)^{74}$.

Con miras a reducir la sustancia misma del contrato relacional, Macneil introdujo la noción de un espectro de contratos, con un extremo discreto y otro relacional ${ }^{75}$. Mientras el extremo discreto estaría basado en explicaciones de la teoría contractual clásica y neoclásica, el extremo relacional haría énfasis en explicaciones más contextuales y desarrolladas (relacionales) ${ }^{76}$. No obstante, Macneil no ofreció una definición operable del término. Desde entonces en la literatura han existido múltiples intentos de definir qué es un contrato relacional, sin que a la fecha se haya encontrado una definición aceptada unánimemente y que tenga operabilidad legal ${ }^{77}$. Algunas sugerencias incluyen como definición un contrato en el que las partes son "incapaces de reducir los términos importantes del arreglo a obligaciones bien definidas"78, lo que "involucra no solo un mero intercambio, sino también un relacionamiento"79, o que es "incompleto y su cumplimiento ocurre hasta cierto punto por amenazas de

73 Feinman, J. M., "Relational Contract Theory in Context", cit., 740.

74 MACNEIL, I. R., "Reflections on Relational Contract Theory after a Neo-classical Seminar", en CAMPBELL, D. et al. (coords.), Implicit Dimensions of Contract: Discrete, Relational, and Network Contracts, Oxford, Hart, 2003, 213, trad. propia; véase también MACNEIL, I. R., "Relational Contract Theory: Challenges and Queries", cit., 879 y ss. Para una evaluación crítica de las variables, véase Feinman, J. M., "Relational Contract Theory in Context”, cit., 742 y ss.

75 Macneil, I. R., "Contracts: Adjustment of Long-Term Economic Relations under Classical, Neoclassical, and Relational Contract Law", cit., 865.

76 Véase CAmpbell, D., "Ian Macneil and the Relational Theory of Contract", cit., 41, con referencias adicionales.

77 Véase Eisenberg, M. A., "Why There Is No Law on Relational Contracts”, cit., 813; Collins, H., "Is a Relational Contract a Legal Concept?", LSE Research Online, 2016, 2, disponible en: http://eprints. 1se.ac.uk/102557/1/Collins_is_a_relational_contract_a_legal_concept_accepted.pdf [consultado el 28 de julio de 2020].

78 Goetz, C. J. y Scott, R. E., "Principles of Relational Contract", Virginia Law Review, University of Virginia School of Law, vol. 67, n. ${ }^{\circ}$ 6, 1981, 1091.

79 Eisenberg, M. A., "Why There Is No Law on Relational Contracts", cit., 816. 
sanciones no legales" 80 . Asimismo, "una relación de negocios de largo plazo que proveerá a ambas partes con rendimientos suficientes para continuar con la relación a pesar de periodos de adversidad considerable con obligaciones indeterminadas e implícitas de adaptación, cooperación y evolución de obligaciones de desempeño, que están hechas a la medida para alcanzar lo necesario para garantizar el éxito de la empresa" 81 . Resulta obvio que los contratos de largo plazo tienen una mayor probabilidad de cumplir con los criterios sugeridos, aunque la duración por sí misma no es necesaria ni suficiente para establecer un contrato relacional ${ }^{82}$. Equiparar contratos relacionales con contratos de largo plazo es una equivocación común ${ }^{83}$. En realidad, todas las relaciones deben contemplarse -a saber, la cercanía de la relación y la complejidad ${ }^{84}$ del contrato-. A pesar de la falta de una definición aceptada universalmente de los contratos relacionales, en gran medida se entiende su existencia como un hecho dado ${ }^{85}$.

Después de su introducción a través de Macneil, los contratos relacionales se han analizado en la academia legal, sociológica y del law-and-economics $^{86}$. La investigación empírica formal (sociológica) del contrato relacional fue reconocidamente dirigida por Stewart Macaulay. Tras estudiar cómo los manufactureros se aproximan a los contratos legales y a la resolución de conflictos ${ }^{87}$, Macaulay llegó a la conclusión de que en bastantes relaciones negociales de intercambio "prácticas relativamente no contractuales" son comunes ${ }^{88}$. Aquí, el rol del derecho de contratos es en realidad mucho menor que el que asumió la teoría contractual tradicional ${ }^{89}$.

80 BAKer, S. у Chоi, A., "Contract's Role in Relational Contract", Virginia Law Review, University of Virginia School of Law, vol. 101, n. ${ }^{\circ} 3,2015,567$.

81 Collins, H., "Is a Relational Contract a Legal Concept?", cit., 18.

82 Véase Eisenberg, M. A., "Why There Is No Law on Relational Contracts", cit., 814 y ss.; Goetz, C. J. y Sсотт, R. E., "Principles of Relational Contract”, cit., 1091.

83 Eisenberg, M. A., "Why There Is No Law on Relational Contracts", cit., 814; Goetz, C. J. y Scott, R. E., "Principles of Relational Contract", cit., 1091; véase también Collins, H., "Is a Relational Contract a Legal Concept?", cit., 9.

84 Véase MacneIl, I. R., "Contracts: Adjustment of Long-Term Economic Relations under Classical, Neoclassical, and Relational Contract Law", cit., 990.

85 Baker, S. y Choi, A., "Contract's Role in Relational Contract”, cit., 568; véase también Posner, E. A., "A Theory of Contract Law under Conditions of Radical Judicial Error", Northwestern University Law Review, vol. 94, n. ${ }^{\circ}$ 3, 2000, 751.

86 Para un resumen de la recepción de la teoría relacional de los contratos en estas áreas de la academia, véase MAcNeIL, I. R., "Relational Contract: What We Do and Do Not Know", cit., 494 y ss., 509 y ss.

87 En su ampliamente conocido trabajo de 1963 sobre "relaciones no contractuales en los negocios" entrevistó a 68 empresarios y abogados; véase MaCAULAY, S., "Non-Contractual Relations in Business: A Preliminary Study”, American Sociological Review, vol. 28, n. ${ }^{\circ}$ 1, 1963, 2, disponible en: https:// media.law.wisc.edu/s/c_8/wcwmt/non-contractual.pdf [consultado el 28 de julio de 2020].

88 Ibid., 12.

89 Esta conclusión se apoya en los estudios conocidos de Lisa Bernstein (1992) de las relaciones contractuales extrajurídicas en la industria del comercio de diamantes en Nueva York. Bernstein encontró que durante una relación vital de intercambio se preferían medidas no jurídicas/relacionales. Sin 
En primer lugar, porque no existe planeación alguna, o, si existe, es muy poca ${ }^{90}$, por lo que los vacíos contractuales se suplen con la costumbre ${ }^{91}$. En segundo lugar, cuando surgen disputas, las partes rara vez hacen uso de las sanciones del derecho contractual debido a sus consecuencias no deseadas ${ }^{92}$. La conclusión de que algunas transacciones se cumplen por sí mismas ${ }^{93}$ es compartida ampliamente por la academia económica -no relacional $^{94}$-, mayoritariamente por la teoría de la elección racional sin costos de transacción y la teoría de juegos. Las partes se aferrarán al contrato y lo ejecutarán lo mejor que puedan solo si mantener su relación es más beneficioso que darla por terminada ${ }^{95}$.

\section{El derecho que regula los contractos relacionales}

\section{A. La teoría relacional como un principio analítico neutro}

Cualquier exploración del derecho que regula los contratos relacionales tiene que empezar por establecer que la teoría contractual relacional en sí misma pretende ser puramente descriptiva ${ }^{96}$. No es prescriptiva en el sentido de asignar consecuencias jurídicas a un contrato denominado relacional, o definiendo un cuerpo normativo de derecho contractual relacional ${ }^{97}$. La teoría de los contratos relacionales es un principio neutro y analítico ${ }^{98}$. Es un microscopio ${ }^{99}$ que hace visible lo que a gran escala no se puede ver a través del lente de los modelos discretistas ${ }^{100}$. Asimismo,

embargo, cuando la relación termina, las partes recurren a la ley y al contrato inicial. Sobre esto, véase Macaulay, S., "The Real and the Paper Deal", cit., 64 y ss.

90 Macaulay, S., "Non-Contractual Relations in Business", cit., 9.

91 Ibid., 13. Por esta razón, en ocasiones se refiere a los contratos relacionales como contratos incompletos, por oposición a contratos completos (discretos); véase Scotт, R. E., "The Case for Formalism in Relational Contract", Northwestern University Law Review, vol. 94, n. . 3, $2000,847$.

92 Macaulay, S., "Non-Contractual Relations in Business", cit., 1, 9. En la mayoría de los casos, las partes querrán continuar su relación de negocios (ibid., 13), y solo acudirán a la planeación y las sanciones legales si ello les da ganancias netas sobre una aproximación no legal; véase ibid., 9 .

93 Collins, H., "Is a Relational Contract a Legal Concept?”, cit., 10.

94 MacneIL, I. R., "Relational Contract Theory: Challenges and Queries”, cit., 883.

95 Collins, H., "Is a Relational Contract a Legal Concept?", cit., 10, con un panorama general de los contratos relacionales en la teoría económica en pp. 9 y ss.

96 Véase MACNEIL, I. R., "Relational Contract Theory: Challenges and Queries", cit., 898; MACNEIL, I. R., "Reflections on Relational Contract Theory after a Neo-classical Seminar", cit., 207, nota 7.

97 Véase Macneil, I. R., "Relational Contract Theory: Challenges and Queries", cit., 898 y ss.; MACNEIL, I. R., "Reflections on Relational Contract Theory after a Neo-classical Seminar", cit., 215; adicionalmente Perritt, H. H. Jr., "Implied Covenant: Anachronism or Augur", Seton Hall Law Review, Seton Hall University School of Law, vol. 20, n. . 4, 1990, 717.

98 MaCneIL, I. R., "Relational Contract Theory: Challenges and Queries", cit., 207; MACNEIL, I. R., "Reflections on Relational Contract Theory after a Neo-classical Seminar", cit., 217.

99 Ibid., 212.

100 Ibid., 215. 
Macneil enfatizaba que, contrario a una creencia popular equivocada, la teoría de los contratos relacionales no es una teoría social completa ${ }^{101}$, ni promueve a propósito ciertos puntos de vista sociales ${ }^{102}$, y especialmente no promueve perspectivas humanitarias $^{103}$. Ni siquiera se preocupa por preservar siempre una relación ${ }^{104}$. La teoría de los contratos relacionales aporta una perspectiva de los contratos que permite obtener conclusiones humanitarias ${ }^{105}$, al requerir contemplar aspectos como la "creación y restricción del poder, [...] integridad de rol, balances de reciprocidad, solidaridad contractual", entre otros ${ }^{106}$.

\section{B. La dimensión prescriptiva de la teoría de los contratos relacionales}

No obstante la pretensión de la teoría de los contratos relacionales de ser descriptiva, esta sí da instrucciones prescriptivas respecto al análisis de los contratos relacionales. Existe una creencia general en la literatura legal y del law-in-society ${ }^{107}$ en el sentido de que los contratos relacionales deben interpretarse de una manera distinta a los contratos discretos ${ }^{108}$. El punto de partida del análisis contractual no debería ser los términos explícitos del contrato ${ }^{109}$, sino la relación subyacente y los entendimientos implícitos -el contexto- ${ }^{110}$. Lo anterior dado que es probable que los problemas más significativos para las partes se encontrarán por fuera de los términos expresos del contrato $^{111}$. Los factores no escritos, no verbales, no comunicados, sirven como guía en la interpretación de dichos términos ${ }^{112}$. Este enfoque es una clara antítesis del enfoque formalista y jerárquico de las teorías clásica/neoclásica de interpretación del contrato $^{113}$. Permite que las cortes, en caso de circunstancias distintas, puedan crear términos que resulten justos ex post, cuando la parte que está en desventaja sufre pér-

101 Ibid., 214.

102 Ibid., 208, 217.

103 Ibid., 207.

104 MacneIL, I. R., "Relational Contract Theory: Challenges and Queries", cit., 899.

105 MacneIL, I. R., "Reflections on Relational Contract Theory after a Neo-classical Seminar", cit., 216.

106 Ibid., 215.

107 Propuestas de la academia del law-and-economics para la interpretación de contratos relacionales incluyen: ignorar las intenciones de las partes y suplir los vacíos objetivamente (punto de vista de eficiencia ex-ante) o dejar los vacíos abiertos y hacer cumplir los términos expresos del contrato (punto de vista literalista); véase Sсотт, R. E., "The Case for Formalism in Relational Contract”, cit., 849 y ss., con referencias adicionales.

108 Collins, H., "Is a Relational Contract a Legal Concept?", cit., 18.

109 MACNEIL, I. R., "Reflections on Relational Contract Theory after a Neo-classical Seminar", cit., 211.

110 Ibid., 207, 217.

111 Ibid., 208, 210.

112 Ibid., 209.

113 Véase MacneIL, I. R., "Contracts: Adjustment of Long-Term Economic Relations under Classical, Neoclassical, and Relational Contract Law”, cit., 894. 
didas devastadoras al hacer uso de los remedios contractuales disponibles ${ }^{114}$. La teoría de los contratos relacionales también reconoce que cuando se redacta un contrato relacional existe una mayor demanda de flexibilidad en los términos o en el uso de vacíos $^{115}$, de manera que el contrato pueda evolucionar a lo largo de su vida útil y pueda adaptarse a las circunstancias variantes en la medida de lo necesario. Si un contrato relacional se estructura en términos muy rígidos, fácilmente pierde su funcionalidad ${ }^{116}$.

\section{El derecho de los contratos relacionales de lege lata y en la literatura}

A pesar de que la teoría de los contratos relacionales ha tenido una amplia acogida en la literatura ("ahora todos somos relacionistas"117), sus implicaciones prácticas de lege lata son pocas. Ni el legislador, ni las cortes, ni la literatura han desarrollado un cuerpo normativo de derecho contractual relacional unilateralmente aplicable ${ }^{118}$. Existe evidencia que muestra que las cortes de common law han adoptado la teoría relacional de los contratos, pero es escasa y dispersa ${ }^{119}$. La literatura ha propuesto un número de reglas especiales -diversas y sin aceptación unánime- que se estiman aplicables únicamente y a todos los contratos relacionales ${ }^{120}$. Entre ellas están el deber de renegociar de buena fe los ajustes de precios equitativos tras un cambio de circunstancias y el deber general de ejecutar de buena fe el contrato, lo que les permite a las cortes ajustar los términos del contrato de manera que una pérdida inesperada sea compartida por las partes, en vez de recaer en una sola de ellas ${ }^{121}$. Como estas reglas carecen de aceptación universal, todavía no existe un concepto general compartido del derecho contractual relacional ${ }^{122}$.

114 Sсотт, R. E., "The Case for Formalism in Relational Contract”, cit., 851, es crítico de la competencia de las cortes para llegar a resultados justos ex post; véase ibid., 859; Posner, E. A., "A Theory of Contract Law under Conditions of Radical Judicial Error", cit., 753 y ss.

115 Macneil, I. R., "Contracts: Adjustment of Long-Term Economic Relations under Classical, Neoclassical, and Relational Contract Law", cit., 990; véase también GoEtz, C. J. y Scotт, R. E., "Principles of Relational Contract”, cit., 1093.

116 MacneIL, I. R., "Contracts: Adjustment of Long-Term Economic Relations under Classical, Neoclassical, and Relational Contract Law", cit., 990.

117 ScotT, R. E., "The Case for Formalism in Relational Contract", cit., 852; en el mismo sentido también CAmpBell, D., "Ian Macneil and the Relational Theory of Contract", cit., 43, 61: "una alternativa superior al contrato clásico".

118 Eisenberg, M. A., "Why There Is No Law on Relational Contracts”, cit., 805, 813.

119 Collins, H., "Is a Relational Contract a Legal Concept?”, cit., 2, con ejemplos en la nota 4.

120 Eisenberg, M. A., "Why There Is No Law on Relational Contracts", cit., 817.

121 Véase Eisenberg, M. A., "Why There Is No Law on Relational Contracts”, cit., 817 y ss., nota 35, para estas y algunas propuestas adicionales, las respectivas referencias en la literatura y una crítica de las reglas propuestas; véase también Collins, H., "Is a Relational Contract a Legal Concept?", cit., 19 y ss. Para un argumento detallado a favor de un pacto implícito de buena fe y negociación justa en contratos relacionales, véase PerritT, H. H. Jr., "Implied Covenant: Anachronism or Augur", cit., 716 y ss.

122 Véase MacneIL, I. R., "Relational Contract: What We Do and Do Not Know”, cit., 525. 
Sin embargo, y en un nivel más granular, ciertas áreas del derecho dan la impresión de adoptar los contratos relacionales. La estructura subyacente de estas áreas es relacional por naturaleza ${ }^{123}$ y los contratos se informan por un nivel alto de complejidad e incertidumbre ${ }^{124}$. Están incluidas “negociación colectiva, derecho laboral, derecho societario, pensiones, condominios, contratos de construcciones, leasing de computadoras, derecho de arrendamiento y derecho del consumo" ${ }^{125}$, entre otras. Si bien esta lista puede ameritar una explicación dogmática más profunda ${ }^{126}$, últimamente ha existido un desviamiento perceptible de ciertas subcategorías de contratos del derecho contractual general ${ }^{127}$. No obstante, es cuestionable afirmar que el desarrollo de normas un tanto relacionales en estas subcategorías ${ }^{128}$ pueda atribuirse a la teoría relacional en vez de a las necesidades prácticas. El efecto directo de la teoría relacional en el derecho contractual de lege lata hasta el momento ha sido mínimo $^{129}$. Quienes anuncian en una oración que "todos los contratos son relacionales, complejos y subjetivos" tienen que admitir que "el derecho contractual [...] no es nada de eso", sino "formal, simple y [...] clásico"130.

\section{La teoría relacional de los contratos a la luz del covid-19}

La pandemia reciente ha hecho visible la constante tensión entre la demanda de estabilidad y la demanda de reacción al cambio, que la teoría relacional de los contratos intenta abordar. Consideramos que Macneil está en lo cierto cuando señala que existe una "estructura social común" que subyace a los contratos. La estructura social subyacente a los contratos afectados por los eventos que siguieron al brote de COVID-19 claramente incluía una economía libre de pandemia. Cuando se ve la manera tan amplia en la que la pandemia ha impactado un número cuantioso de contratos, se vuelve evidente una vez más qué tan cuestionable es el concepto de presentificación que tiene el derecho contractual tradicional. Resulta obvio que las partes no consideraron el evento de una pandemia mundial al momento de la formación del

123 MacneIL, I. R., "Contracts: Adjustment of Long-Term Economic Relations under Classical, Neoclassical, and Relational Contract Law", cit., 858.

124 Véase Goetz, C. J. y Scott, R. E., "Principles of Relational Contract”, cit., 1092.

125 MacneIl, I. R., "Relational Contract: What We Do and Do Not Know”, cit., 494; véase asimismo Collins, H., "Is a Relational Contract a Legal Concept?", cit., 1, nota 2, con referencias adicionales; Collins, H., "Introduction: The Research Agenda of Implicit Dimensions of Contracts", en CAmpbell, D. et al. (coord.), Implicit Dimensions of Contract: Discrete, Relational, and Network Contracts, Oxford, Hart, 2003, 18; Goetz, C. J. y Scotт, R. E., "Principles of Relational Contract", cit., 1091; BAKER, S. y CHOI, A., "Contract's Role in Relational Contract”, cit., 567.

126 Véase Eisenberg, M. A., "Why There Is No Law on Relational Contracts", cit., 820 y ss.

127 Feinman, J. M., "Relational Contract Theory in Context", cit., 744.

128 Véase Feinman, J. M., "Relational Contract Theory in Context”, cit., 744 y ss., en mayor detalle.

129 Feinman, J. M., "Relational Contract Theory in Context", cit., 737.

130 Sсотт, R. E., "The Case for Formalism in Relational Contract”, cit., 852; énfasis añadido. 
contrato. Además, buscar preeminentemente en el acuerdo original para responder cómo se deben ajustar los cambios imprevisibles producidos por la pandemia probablemente resultará devastador para una parte e inesperadamente beneficioso para la otra. Por lo tanto, la tercera proposición central de Macneil es cierta en tanto todos los elementos de las relaciones que rodean al contrato que pueden llegar a afectar significativamente la transacción deben ser tenidas en cuenta al analizar el contrato. Como lo prescribe la teoría relacional, al interpretar los contratos afectados por la pandemia las cortes tendrán que revisar el contexto -y, de manera consecuente, reconocer el impacto de la pandemia-.

\section{Evaluación}

El recuento anterior de la teoría del solidarismo contractual y de la teoría relacional de los contratos muestra que existen caminos viables para enfatizar la función social y la realidad de los contratos. Ambas teorías pueden ayudar a informar un nuevo derecho contractual que ofrezca respuestas justas y flexibles a un incumplimiento causado por circunstancias extraordinarias e imprevistas, tal y como la pandemia actual. Ese cambio estructural está en mora de hacerse, y ello se demuestra por el hecho de que a la luz del Covid-19 varios países han tenido que adoptar una legislación ad hoc de emergencia para amortiguar las consecuencias que de otra manera habrían resultado devastadoras para las partes en desventaja en contratos de largo plazo. La pandemia ha visibilizado las tendencias asociales del derecho contractual. Repentinamente, se hizo palmaria la necesidad de hacer el derecho contractual más "justo", "social" y "equitativo". Sin embargo, parece obvio que estos principios deberían estar en el centro del derecho contractual en cualquier momento, y no únicamente en la hipótesis de una pandemia global. Aun así, fueron la cantidad masiva de contratos afectados por COVID-19 y las circunstancias sin precedentes lo que obligó a los legisladores a actuar.

Tras haber examinado la teoría del solidarismo contractual y la teoría de los contratos relacionales parece retador determinar cuál de las dos escoger como teoría que informe los cambios que deberían venir después de la reflexión. Es cuestionable si se puede escoger alguna, dado que el solidarismo es una teoría eminentemente prescriptiva, mientras que la teoría relacional es principalmente descriptiva. Adicionalmente, surge la pregunta de si la escogencia de una de las teorías sobre la otra traería beneficio alguno para la tarea que examinamos. Creemos que este no es el caso. Un examen más detallado revela una gran cantidad de puntos en común entre el solidarismo y la teoría relacional. Donde termina ese común denominador las teorías parecen complementarse una a la otra sin problema. Por lo tanto, puede resultar fructífero desarrollar una mentalidad inclusiva cuando se busca inspiración teórica/ filosófica para una revisión social del derecho contractual.

Al buscar semejanzas entre las dos teorías es notorio, primero, que ambas luchan por establecer qué es un contrato (teoría relacional) o qué debería ser (solida- 
rismo), más allá de un intercambio entre partes que carecen de un interés social y negocian con estricta independencia. Ambas teorías enfatizan que un contrato es una institución utilizada por seres humanos que también hacen parte de una sociedad. Resulta ilusorio asumir que estas circunstancias no tienen (teoría relacional) o no deberían tener (solidarismo) una influencia en el contrato en sí mismo. Segundo, el solidarismo promueve la imagen del hombre como un ser social que como tal depende de otros; la teoría relacional se basa en el reconocimiento de que todos estamos inmersos en relaciones, lo que conduce a una dependencia.

Un tercer paralelo fuerte entre ambas teorías es la razón de su respectiva creación. El solidarismo surgió como una respuesta al excesivo individualismo en los contratos; la teoría relacional de los contratos se creó en respuesta al paradigma del contrato discreto del derecho contractual tradicional, el cual es bastante individualista. El cuarto y probablemente más obvio punto común entre ambas teorías es que la "solidaridad contractual" es uno de los diez patrones y normas comunes del comportamiento contractual de Macneil. De hecho, Macneil en repetidas ocasiones se refiere a la solidaridad contractual, por ejemplo, nombrándola como uno de los aspectos que la teoría relacional debe considerar. Quinto, mientras el solidarismo apunta a promover puntos de vista humanitarios, la teoría relacional permite cuando menos obtener conclusiones humanitarias. Revisando las áreas del derecho que se consideran "relacionales por naturaleza" y se han desarrollado en distintas subcategorías del derecho contractual -por ejemplo, derecho de arrendamiento y derecho laboral-, muestra que en estos campos la necesidad del solidarismo es apremiante.

Una sexta similitud adicional son las asunciones acerca de los deberes de las partes y el Estado (solidarismo) y las observaciones de la conducta real de los contratantes (teoría relacional). La teoría del solidarismo asume un lazo de solidaridad entre las partes y una necesidad de reconciliar sus intereses. El solidarismo exige que las partes cumplan con los deberes de lealtad, solidaridad y buena fe al colaborar continuamente a lo largo de la vida útil del contrato. Así, las partes tienen varios deberes de cooperación, uno de ellos siendo el deber de renegociar, como se argumentó anteriormente. Según el solidarismo, el contrato también tiene una función social, que puede ser entendida como la potestad de intervención del Estado. Las observaciones sobre la teoría relacional de los contratos que ha hecho la academia del law-and-society muestran un panorama muy similar al de estas reglas y deberes prescritos por el solidarismo. Los estudios de Macaulay muestran que existen casos en los que la solidaridad es una práctica de las partes contratantes. Las partes tienden a aceptar concesiones y beneficios mutuos y, en caso de un incumplimiento, intentan acomodarse, en lugar de ejercer sus derechos, reconciliando así sus intereses. Lo anterior ocurre especialmente en relaciones de negocios de largo plazo. Las partes intentan mantener el contrato vivo y le son leales, aun cuando las circunstancias cambian. La renegociación parece ocurrir a menudo en la realidad, especialmente cuando las partes no acordaron todos los términos en el contrato inicial. Finalmente, la teoría relacional de los contratos también acepta una potestad del Estado de 
analizar el contrato y exige que la interpretación debe partir del contexto (que es relacional, y por lo tanto social).

\section{Reflexiones finales}

En conclusión, en términos de derecho contractual, la pandemia se puede enmarcar como un llamado de atención a los legisladores para empezar a desarrollar un derecho contractual que esté informado por el solidarismo y la propuesta relacional. Esto proveería reglas contractuales que pasen la prueba de la justicia en todo momento y que no requieran ajustes a través de legislación de emergencia en el marco de una crisis. Tanto el lente principalmente descriptivo de la teoría relacional de los contratos como la teoría del solidarismo contractual, que es predominantemente prescriptiva, aportarán un apoyo invaluable en la redacción y construcción de un nuevo derecho de contratos, particularmente en los casos en los que las figuras de la fuerza mayor o la imprevisión no son suficientes para responder a las necesidades de los contratantes en dificultades.

\section{Referencias}

Alterini, A., Treinta estudios de derecho privado, Bogotá, Temis-Pontificia Universidad Javeriana, 2011.

Ambrozini, L. C. S. y Martinelli, D. P., "Contratos formales y relacionales entre organizaciones: proposición de un modelo para el análisis de las características transaccionales y las estructuras de gobernanza a partir de casos comparativos", Revista de Administração, vol. 52, n. . 4, 2017, 374-391.

BAKer, S. y ChOI, A., "Contract's Role in Relational Contract", Virginia Law Review, University of Virginia School of Law, vol. 101, n. ${ }^{\circ} 3,2015,559-608$.

Benetti Timm, L. "La función social del derecho contractual en el código civil brasileño: justicia distributiva vs. eficiencia económica”, Revista de Instituciones, Ideas y Mercados, $\mathrm{n}^{\circ}$ 52, 2010, 5-51.

Bernal, M., "La contratación proactiva dentro de las nuevas visiones del contrato", Vniversitas, Pontificia Universidad Javeriana, vol. 64, n. ${ }^{\circ}$ 130, 2011, 21-52.

Bernal, M., El deber de coherencia en el derecho colombiano de los contratos, Bogotá, Pontificia Universidad Javeriana, 2013. 
Bernstein, L., "Opting Out of the Legal System: Extralegal Contractual Relations in the Diamond Industry", The Journal of Legal Studies, University of Chicago Press, vol. 21, n. $1,1992,115-158$.

Betti, E., Teoría general de las obligaciones, t. I, J. L. de los Mozos (trad.), Madrid, Revista de Derecho Privado, 1969.

Bianca, M., Derecho civil, III, El contrato, F. Hinestrosa y É. Cortés (trads.), Bogotá, Universidad Externado de Colombia, 2007.

Bourgeois, L., La solidarité, Villeneuve-d'Ascq, Presses Universitaires du Septentrion, 1998.

Branco, G., Função social dos contratos, São Paulo, Saraiva, 2009.

BrANCO, G. L. C., "Libertad contractual y su funcionalización: orientación metodológica y lenguaje utilizados por la comisión elaboradora del código civil brasileño”, Vniversitas, Pontificia Universidad Javeriana, n. ${ }^{\circ} 123,2011$, 347-371.

BrantT, M. G., "La exigencia de exterioridad en el caso fortuito: su construcción a partir de la distribución de los riesgos del contrato", Revista de Derecho de la Pontificia Universidad Católica de Valparaíso, n. ${ }^{\circ}$ 33, 2009, 39-102.

Campbell, D., "Ian Macneil and the Relational Theory of Contract", en Campbell, D. (coord.), Relational Theory of Contract: Selected Works of Ian Macneil, London, Sweet \& Maxwell, 2001, 3-58.

CÁrdenas, J. P., "Causa extraña como eximente de responsabilidad”, en CAStro, M. (coord.), Derecho de las obligaciones, t. III, Bogotá, Universidad de los Andes, 2018, 415-472.

CARo, J., "La teoría de la imprevisión”, en CAStro, M. (coord.), Derecho de las obligaciones, t. II, Bogotá, Universidad de los Andes, 2016, 121-162.

Collins, H., "Is a Relational Contract a Legal Concept?", LSE Research Online, 2016, disponible en: http://eprints.lse.ac.uk/102557/1/Collins_is_a_relational_ contract_a_legal_concept_accepted.pdf [consultado el 28 de julio de 2020].

Collins, H., "Introduction: The Research Agenda of Implicit Dimensions of Contracts", en CAMPBELL, D. K. (coord.), Implicit Dimensions of Contract: Discrete, Relational, and Network Contracts, Oxford, Hart Publishing, 2003, 1-24. 
Courdier-Cuisiner, A. S., Le solidarisme contractuel, Paris, Litec-Editions du JurisClasseur, 2006.

Duguit, L., Las transformaciones generales del derecho privado desde el Código de Napoleón, Madrid, Francisco Beltrán, 1920.

EIsenberg, M. A., "Why There Is No Law on Relational Contracts", Northwestern University Law Review, vol. 94, n. ${ }^{\circ}$ 3, 2000, 805-821.

Feinman, J. M., "Relational Contract Theory in Context", Northwestern University Law Review, vol. 94, n. ${ }^{\circ}$ 3, 2000, 737-748.

FRANCO, J. A., "La excesiva onerosidad sobrevenida en la contratación mercantil: una aproximación desde la perspectiva de la jurisdicción civil en Colombia", Revista de Derecho Privado, Universidad Externado de Colombia, n. ${ }^{2} 23,2012$, 233-265.

Gebrekidan, S., "Frente al coronavirus los gobiernos van amasando poder (no todos son autócratas)", New York Times, 1 de abril de 2020, disponible en: https:// www.nytimes.com/es/2020/04/01/espanol/coronavirus-decreto-emergencia-autocratas.html [consultado el 28 de julio de 2020].

Goetz, C. J. y Scott, R. E., "Principles of Relational Contract”, Virginia Law Review, vol. 67, n. ${ }^{\circ} 6,1981,1089-1150$.

Goldenberg, J. L., “A propósito del Covid-19: incapacidad sobreviniente de pago y ‘fuerza mayor social'”, El Mercurio, 4 de abril de 2020. https://www.elmercurio.com/Legal/Noticias/Opinion/2020/04/27/A-proposito-del-COvID19-incapacidad-sobreviniente-de-pago-y-fuerza-mayor-social.aspx, [consultado el 28 de julio de 2020].

Hinestrosa, F., "Función, límites y cargas de la autonomía privada", Revista de Derecho Privado, Universidad Externado de Colombia, n. ${ }^{\circ}$ 26, 2014, 5-39.

Hinestrosa, F., “Teoría de la imprevisión”, Revista de Derecho Privado, Universidad Externado de Colombia, n. ${ }^{\circ}$ 39, 2020, 9-29.

Macaulay, S., "The Real and the Paper Deal: Empirical Pictures of Relationships, Complexity and the Urge for Transparent Simple Rules", en Campbell, D. et al. (coords.), Implicit Dimensions of Contract: Discrete, Relational, and Network Contracts, Oxford, Hart Publishing, 2003, 775-804. 
Macaulay, S., "Non-Contractual Relations in Business: A Preliminary Study", American Sociological Review, vol. 28, n. ${ }^{\circ}$ 1, 1963, disponible en: https://media.law. wisc.edu/s/c_8/wcwmt/non-contractual.pdf [consultado el 28 de julio de 2020].

MacneIL, I. R., "Reflections on Relational Contract Theory after a Neo-classical Seminar", en Campbell, D. et al. (coords.), Implicit Dimensions of Contract: Discrete, Relational, and Network Contracts, Oxford, Hart, 2003, 207-218.

MACNeIL, I. R., "Relational Contract Theory: Challenges and Queries", Northwestern University Law Review, vol. 94, n. . 3, 2000, 877-908.

MacneIL, I. R., "Relational Contract: What We Do and Do Not Know", Wisconsin Law Review, University of Wisconsin Law School, vol. 1985, n. . 3, 1985, 483526.

MacneIL, I. R., "Contracts: Adjustment of Long-Term Economic Relations under Classical, Neoclassical, and Relational Contract Law”, Northwestern University Law Review, vol. 72, n. ${ }^{\circ}$ 6, 1978, 854-905.

Mantilla, F., "El solidarismo contractual en Francia y la constitucionalización de los contratos en Colombia", Revista Chilena de Derecho Privado, n. ${ }^{\circ} 16,2011$, 187-241.

Martínez OchoA, S., "Teoría relacional de los contratos: una visión alternativa del derecho de contratos", Revista de Derecho Privado, n. ${ }^{\circ}$ 35, 2005, 203-229.

Martins-Costa, J., "Reflexões sobre o princípio da função social dos contratos", Revista Direito GV, vol. 1, n. ${ }^{\circ}$ 1, 2005, 41-66.

MazeAud, D., "Le nouvel ordre contractuel", Revue des contrats, n. ${ }^{\circ}$ 1, 2003, 295.

Momberg Uribe, R., "La revisión del contrato por las partes: el deber de renegociación como efecto de la excesiva onerosidad sobreviniente", Revista Chilena de Derecho, vol. 37, n. ${ }^{\circ}$ 1, 2010, 43-72.

Momberg Uribe, R. y Pino Emhart, A., "Los contratos de larga duración en la edición 2016 de los Principios Unidroit sobre contratos comerciales internacionales", Revista Chilena de Derecho Privado, n. . 30, 2018, 163-191.

Perritt, H. H. Jr., "Implied Covenant: Anachronism or Augur", Seton Hall Law Review, Seton Hall University School of Law, vol. 20, n. ${ }^{\circ} 4$, 1990, 683-774. 
Pico Zúñiga, F. A. y Rojas Quiñones, S. A., Solidarismo contractual. El deber de cooperación y su repercusión en la responsabilidad civil, Bogotá, Ibáñez, 2013.

Posner, E. A., “A Theory of Contract Law under Conditions of Radical Judicial Error”, Northwestern University Law Review, vol. 94, n. . 3, 2000, 749-774.

Revista Dinero, "Los contratos en la era del coronavirus", 18 de abril de 2020, disponible en: https://www.dinero.com/empresas/articulo/asi-funcionan-los-contratos-en-la-era-del-coronavirus/284144, [consultado el 28 de julio de 2020].

Rojas, S., "Responsabilidad civil por falta de cooperación contractual. Relevancia en tiempos del covid-19”, In Casu - Blog, Instituto Colombiano de Responsabilidad Civil y del Estado, 2020, disponible en: https://www.iarce.com/responsabilidadcivil-por-falta-de-cooperacion-contractual-relevancia-en-tiempos-del-COvID-19/ [consultado el 28 de julio de 2020].

Scotт, R. E., "The Case for Formalism in Relational Contract”, Northwestern University Law Review, vol. 94, n. . 3, 2000, 847-876.

Solarte, A., "La buena fe contractual y los deberes secundarios de conducta", Vniversitas, Pontificia Universidad Javeriana, vol. 53, n. ${ }^{\circ}$ 108, 2004, 281-315.

Ternera, F., "Las pérdidas fortuitas de los bienes debidos: Teoría de los riesgos de los contratos sinalagmáticos”, en CAstro, M. (coord.), Derecho de las obligaciones, t. I, Bogotá, Universidad de los Andes, 2011, 477-504.

VIDAL,A., "Cumplimiento e incumplimiento contractual en el código civil: una perspectiva más realista”, Revista Chilena de Derecho, vol. 34, n. ${ }^{\circ}$ 1, 2007, 41-59.

Wilhelmsson, T., “'Social Force Majeure'. A New Concept in Nordic Consumer Law", Journal of Consumer Policy, n. ${ }^{\circ}$ 13, 1990, 1-14. 